\title{
Who wants to be a surgeon? A study of 300 first year medical students Thomas HS Fysh*1, Geraint Thomas ${ }^{2}$ and Harold Ellis ${ }^{3}$
}

\author{
Address: ${ }^{1}$ Department of Surgery, RCHT Treliske, Treliske, Truro, Cornwall, TR1 3LJ, UK, ${ }^{2}$ Department of Surgery, The Royal Free Hospital, Pond \\ St., London NW3 2QG, UK and 'Department of Anatomy, Hodgkin Building, Guy's Campus, Guy's King's and St Thomas' School of Medicine, St \\ Thomas' Street, London SE1 1UL, UK \\ Email: Thomas HS Fysh* - thomas.fysh@btinternet.com; Geraint Thomas - geraint.thomas@gmail.com; Harold Ellis - harold.ellis@kcl.ac.uk \\ * Corresponding author
}

Published: 19 january 2007

BMC Medical Education 2007, 7:2 doi:10.1 186/1472-6920-7-2
Received: I June 2006

Accepted: 19 January 2007

This article is available from: http://www.biomedcentral.com/1472-6920/7/2

(c) 2007 Fysh et al; licensee BioMed Central Ltd.

This is an Open Access article distributed under the terms of the Creative Commons Attribution License (http://creativecommons.org/licenses/by/2.0), which permits unrestricted use, distribution, and reproduction in any medium, provided the original work is properly cited.

\begin{abstract}
Background: While medicine in general is becoming more female-dominated, women are still under-represented in surgery. Opinion is divided as to whether this is due to lifestyle considerations, disinterest or perceived discrimination. It is not clear at what stage these careers decisions are made.
\end{abstract}

Methods: 300 first year medical students at Guy's King's and St Thomas' School of Medicine (GKT) were asked their view on possible career choices at this stage.

Results: While men represented only $38 \%$ of the student population, they represented over twothirds of the students wishing to pursue a career in surgery.

Women still opt for general practice and paediatrics.

Conclusion: Surgery is a disproportionately unpopular career choice of the female first-year medical students of GKT compared to the male students. It appears that the choice is freely made and, at this stage at least, does not represent concerns about compatibility with lifestyle.

\section{Background}

While the medical profession was formerly a male-dominated one, it is now the case that women are actually over represented in medicine $[1,2]$. The field of surgery, however, is slow to catch up. Although efforts are being employed in the Royal colleges, hospitals and medical schools to reverse this phenomenon, it is still very apparent that, while good results are being achieved recruiting ethnic minorities to surgery, women are still grossly under-represented [1,3-5]. It is conceded that numbers of women entering surgery are rising, but this is at a rate far lower than one would expect [6], with some fields such as orthopaedic and cardiothoracic surgery faring worse than others: A recent study found that while the percentage of female medical students has risen by over $40 \%$ since 1970 , the proportion of female orthopaedic surgeons has risen by only $8 \%$. Women, it appears, are still opting for general practice and paediatrics.

Some projects have looked into why this trend still exists: The glass ceiling phenomenon is explored in depth [7] along with discrimination [8] and the possibility that women (in general), simply do not want to be surgeons. Results are surprisingly varied. Many convincing studies have found that that lifestyle considerations, training and 'women friendliness' were most important to women 
(especially when directly questioned) $[3,9,10]$ with some concluding that discrimination and male bias is still rife $[3,11]$. Others, however, conclude that while these factors are more important to women than to men, women still rate interest and job satisfaction significantly higher than any other motivation [12-17]. A 1996 study of Canadian female surgeons sums up the situation quite well when it suggests that although most female surgeons did not feel actively discriminated against, the perception of discrimination during surgical training was present [11]. Whatever the findings, it is widely accepted that female role models are rare in surgery and that this should be addressed $[8,18]$.

This project aims to discover the career intentions of the first year medical students at Guy's King's and St Thomas' medical school early on in their training. More specifically it aims to determine whether female medical students would like to be surgeons, or whether they prefer other specialties from the outset.

\section{Methods}

300 first year medical students were surveyed in their first two weeks at Guy's, King's and St Thomas' Medical School, London (i.e., before they had had more than a few days exposure to their preclinical teaching). They were surveyed over a two week period after anatomy dissection classes and asked details about their ethnicity, gender and education. They were then asked what they would like to specialize in, whether they thought this is what they would specialize in and if not, then why not. The questionnaire is shown in the figure. Significance was determined using chi-squared testing.

\section{Results}

All 300 surveys were completed and used (100\% response rate).

When compared to the British Medical Association demographics [22], it is seen that the ethnic distribution of GKT Students is significantly different to the UK average for $2003\left(\mathrm{X}^{2}>50, \mathrm{df}=4, \mathrm{P}<0.001\right)$. The number of nonwhite students is higher.

Analysis of the population is shown in table 1. It can be seen that surgery is the single most popular career choice of first year medical students. Medicine and general practice follow, although the proportion of students who are undecided forms almost a quarter of the student body.

It is seen in table 1 that $18 \%(33 / 185)$ of women on entry into medical school intend to train as surgeons. The null hypothesis that the proportion of women who choose surgery is equal to the proportion of men who wish to do surgery can be tested using a chi squared test with one degree of freedom. Surgery was chosen by $50 \%$ of men $(33 / 185)$. It is found that $X^{2}=35.7(P<0.001)$. Similarly, a significantly higher proportion of women intend to pursue careers in general practice $\left(\mathrm{X}^{2}=4.1, \mathrm{df}=1, \mathrm{P}<0.05\right)$ and paediatrics $\left(\mathrm{X}^{2}=7.3, \mathrm{df}=1, \mathrm{P}<0.01\right)$, while hospital medicine attracts similar proportions (no significant difference between sexes, $\left.\mathrm{X}^{2}=0.9, \mathrm{df}=1, \mathrm{P}>0.1\right)$. Other specialties were difficult to evaluate due to low numbers.

While $22.3 \%$ of students did not show a career preference at this stage, $18.2 \%$ of students said that they thought they might end up pursuing different careers from those they had initially chosen. By far the most common reason given was that their interests might change (60\%), although other areas of concern included competition ability and religion. Family and life-compatibility concerns were mentioned on four occasions, twice for medicine and twice for surgery.

Amongst different ethnicities, there was no significant difference between the observed and expected numbers of students choosing surgery as a career $\left(\mathrm{X}^{2}=2.0, \mathrm{df}=5, \mathrm{P}>\right.$ 0.1 ). Numbers were too small to look at each specialty separately, so each ethnic group was divided into 'surgery' and 'not-surgery' for the purposes of this test. Even so, some groups remained small (e.g. for Arab students, $\mathrm{n}=$ 9). This affects significance and is discussed in the 'discussion' section. The same was true for education $\left(\mathrm{X}^{2}=4.5, \mathrm{df}\right.$ $=2, \mathrm{P}>0.1)$. The chi squared values are derived from the data in table 1.

\section{Discussion}

Our data suggest that while the proportion of women on entry to medical school wishing to pursue a surgical career is around $18 \%$ (a high proportion compared to other studies $[1,6,19])$, this compares to over $50 \%$ of male students at the same stage. This is of special concern since men form only $38 \%$ of the sample population. Specialties such as general practice and paediatrics continue to attract female medical students.

By allowing students to comment on why they did not think they would pursue a certain line of work, despite an interest in the area, it was possible to conclude that an interest in the line of work was much more important than life-style considerations at this stage, confounding the results of other studies $[12-14,20]$ This finding is valuable since it reflects career intentions of students before exposure to (and possible bias by) the system; lifestyle considerations appear to be less important at this stage and were quoted only four times. It is important to stress that some other studies demonstrate that lifestyle probably becomes an important consideration later on in one's career. This said, a cohort study has shown that while an individual's career preference might change over time, the overall pro- 
Table I: Career Intentions of 300 First-year Medical Students (numbers and percentage choice according to sex, ethnicity and schooling).

\begin{tabular}{|c|c|c|c|c|c|c|c|c|c|c|c|c|}
\hline NUMBERS & All & Men & Women & Chinese & Arab & African & All Asian & Caucasian & Not disclosed & Post Grad & Private & State \\
\hline A\&E & 1 & 1 & 0 & 0 & 0 & 0 & 0 & 1 & 0 & 0 & 1 & 0 \\
\hline $\begin{array}{l}\text { Sports } \\
\text { Medicine }\end{array}$ & I & 1 & 0 & 0 & 0 & 0 & 0 & 1 & 0 & 0 & 0 & 1 \\
\hline Anaesthetics & 2 & 0 & 2 & 0 & 0 & 0 & 0 & 2 & 0 & I & 1 & 1 \\
\hline Pathology & 3 & 0 & 3 & 0 & 0 & 0 & 0 & 3 & 0 & I & 3 & 0 \\
\hline Psychiatry & 8 & I & 7 & 0 & I & 0 & 3 & 3 & I & 2 & I & 7 \\
\hline Obs \& Gynae & & I & 8 & 0 & 0 & 0 & 2 & 6 & I & 0 & 4 & 4 \\
\hline Paediatrics & 20 & 2 & 18 & 3 & I & 2 & 2 & 11 & I & 3 & 7 & 11 \\
\hline $\begin{array}{l}\text { General } \\
\text { Practice }\end{array}$ & 32 & 7 & 25 & 2 & 1 & 1 & 11 & 17 & I & 3 & 11 & 17 \\
\hline Medicine & 66 & 22 & 44 & 5 & 2 & 6 & 21 & 32 & 2 & 12 & 20 & 35 \\
\hline Don't Know & 67 & 22 & 45 & 7 & 2 & 5 & 22 & 27 & 2 & 10 & 24 & 33 \\
\hline Surgery & 91 & 58 & 33 & 11 & 2 & 6 & 28 & 39 & 4 & 16 & 38 & 33 \\
\hline Totals & 300 & 115 & 185 & 28 & 9 & 20 & 89 & 142 & 12 & 48 & 110 & 142 \\
\hline PERCENT & All & Men & Women & Chinese & Arab & African & All Asian & Caucasian & Not disclosed & Post Grad & Private & State \\
\hline A\&E & 0.3 & 0.9 & 0.0 & 0.0 & 0.0 & 0.0 & 0.0 & 0.7 & 0.0 & 0.0 & 0.9 & 0.0 \\
\hline $\begin{array}{l}\text { Sports } \\
\text { Medicine }\end{array}$ & 0.3 & 0.9 & 0.0 & 0.0 & 0.0 & 0.0 & 0.0 & 0.7 & 0.0 & 0.0 & 0.0 & 0.7 \\
\hline Anaesthetics & 0.7 & 0.0 & 1.1 & 0.0 & 0.0 & 0.0 & 0.0 & 1.4 & 0.0 & 2.1 & 0.9 & 0.7 \\
\hline Pathology & 1.0 & 0.0 & 1.6 & 0.0 & 0.0 & 0.0 & 0.0 & 2.1 & 0.0 & 2.1 & 2.7 & 0.0 \\
\hline Psychiatry & 2.7 & 0.9 & 3.8 & 0.0 & 11.1 & 0.0 & 3.4 & 2.1 & 8.3 & 4.2 & 0.9 & 4.9 \\
\hline Obs \& Gynae & 3.0 & 0.9 & 4.3 & 0.0 & 0.0 & 0.0 & 2.2 & 4.2 & 8.3 & 0.0 & 3.6 & 2.8 \\
\hline Paediatrics & 6.7 & 1.7 & 9.7 & 10.7 & 11.1 & 10.0 & 2.2 & 7.7 & 8.3 & 6.3 & 6.4 & 7.7 \\
\hline $\begin{array}{l}\text { General } \\
\text { Practice }\end{array}$ & 10.7 & 6.1 & 13.5 & 7.1 & 11.1 & 5.0 & 12.4 & 12.0 & 8.3 & 6.3 & 10.0 & 12.0 \\
\hline Medicine & 22.0 & 19.1 & 23.8 & 17.9 & 22.2 & 30.0 & 23.6 & 22.5 & 16.7 & 25.0 & 18.2 & 24.6 \\
\hline Don't Know & 22.3 & 19.1 & 24.3 & 25.0 & 22.2 & 25.0 & 24.7 & 19.0 & 16.7 & 20.8 & 21.8 & 23.2 \\
\hline Surgery & 30.3 & 50.4 & 17.8 & 39.3 & 22.2 & 30.0 & 31.5 & 27.5 & 33.3 & 33.3 & 34.5 & 23.2 \\
\hline Totals & 100.0 & 100.0 & 100.0 & 100.0 & 100.0 & 100.0 & 100.0 & 100.0 & 100.0 & 100.0 & 100.0 & 100.0 \\
\hline
\end{tabular}

Data used to derive chi-squared values.

portions remain similar throughout [21]. It is not our intention to reproduce this finding, but rather to provide an overview of the career intentions of medical students at the earliest possible opportunity in their training. Consequently, no cohort study was carried out. This is discussed further in the 'study limitations' section.

Our study confirms the findings of other groups by showing little difference in the career preferences of graduates compared to non-graduates [19], and shows no significant preference for surgery amongst any ethnic group, although it is conceded that numbers amongst some ethnicities were small and for this finding to be further validated, a larger sample would be desirable. Other study limitations are discussed in the following text.

This survey represents the views of the first year medical students in their first term at medical school; it is the study's express intention to look at the career intentions of this group before exposure to the system, and it is accepted that their opinions may change. Although it would certainly be interesting to follow up the sample as a cohort in the years to come as an additional project, it falls beyond the aim of the project at this time.

It should also be noted that the study is set in one UK medical school (due to issues of access and practicality) and it is conceded that extra student numbers would lend statistical power to the findings. We were unable to find any other UK studies which looked specifically at the career intentions of first year medical students with which to compare our results. Many of the other studies quoted were completed outside the UK and some time ago. They therefore involved very different student populations and are, consequently, difficult to compare reliably.

It is also alluded to in the 'Results' section that the ethnographic make-up of our student sample is not representative of the UK population as a whole. It is accepted that, while our results are statistically significant, they are not 


\section{Figure 1. Career Intentions of Medical Students}

This questionnaire is confidential- your details will not be disclosed to any third party and are taken only for follow-up purposes.

1. Name

2. Age

3. Sex male female

4. Ethnicity

Bangladeshi

Black Other.

Black African

Irish

Chinese

Other (please specify) ........

Black Caribbean

Indian

White

5. Where did you go to school?

State School, UK

Private School, UK

Abroad

6. Where have you come from?

School

Gap Year

Post Graduate (degree(s) held?)

Other

10. What would you like to end up doing?

Medicine

Surgery

Obstetrics and Gynaecology

Psychiatry

General Practice

Other

what?

Don't know

11. What do you think you will end up doing?

Medicine

Surgery

Obstetrics and Gynaecology

Psychiatry

General Practice

Other

what?

Don't know

12. If there was a difference between 10 and 11 , what are the reasons for this?

Figure I

Study Questionnaire. 
necessarily representative of the UK medical student population as a whole and that every UK medical school would have to be surveyed for our conclusions to be applied nationwide.

It is also noted that the study itself does not detail why students chose the careers they did and so it is difficult to comment on this. It does, however, provide comment on why there might be a difference in intended as opposed to their own predicted future careers. Reasons for not choosing a specific career (e.g. lifestyle considerations) were omitted from the questionnaire so as not to lead the responder into a particular answer.

\section{Conclusion}

The primary conclusion to be drawn from our study is that the women surveyed simply do not want to be surgeons: None of the sample group had experienced surgery (and could not, therefore, have been put off the idea) and only two out of nearly 200 women expressed concerns about lifestyle, contrary to convincing evidence gathered from women at later stages in their careers. One can only guess as to why this should be but it is perhaps the case that views held prior to entering medical school have lead some women to believe that surgery is an unsuitable option for them.

Although competition and selection is inevitable in a surgical career, being female should be no reason to avoid one. Furthermore, the surgical profession is under increasing pressure to open its doors to a wider selection of medical graduates. The simple argument is, that by increasing the numbers of applicants, one is more likely to appoint the best candidate for the post. If it is the case that gender stereotyping exists from an early age, then it should be discouraged. This has been achieved in medicine as a whole and there is no obvious reason why it could not be done for surgery.

\section{Competing interests}

The author(s) declare that they have no competing interests.

\section{Authors' contributions}

TF is the primary author, conceived of the study, designed it and carried it out. GT carried out the statistical analysis. HE was the department supervisor and acted in an advisory capacity.

\section{References}

I. Lambert TW, Goldacre MJ: Career destinations and views in 1998 of the doctors who qualified in the United Kingdom in 1993. Med Educ 2002, 36(2): 193-8.

2. Goldacre M, Davidson J, Lambert T: Country of training and ethnic origin of UK doctors: database and survey studies. $B M$ ] 2004, 329:597. Accessed July 2006.
3. Williams C, Cantillon P: A surgical career? The views of junior women doctors. Med Educ 2000, 34(8):602-7.

4. Goldacre MJ, Davidson JM, Lambert TW: Career choices at the end of the pre-registration year of doctors who qualified in the United Kingdom in 1996. Med Educ 1999, 33(12):882-9.

5. Razali SM: Medical school entrance and career plans of Malaysian medical students. Med Educ 1996, 30(6):418-23.

6. Blakemore LC, Hall JM, Biermann JS: Women in surgical residency training programs. J Bone Joint Surg Am 2003, 85A(I 2):2477-80.

7. McManus IC, Sproston KA: Women in hospital medicine in the United Kingdom: Glass ceiling, preference, prejudice or cohort effect? J Epidemiol Community Health 2000, 54(I): 10-6.

8. Ferris LE, Mackinnon SE, Mizgala CL, McNeill I: Do Canadian female surgeons feel discriminated against as women? CMAJ I 54(I):21-7. I 996 Jan I

9. Redman S, Saltman D, Straton J, Young B, Paul C: Determinants of career choices among women and men medical students and interns. Med Educ 1994, 28(5):36I-7I.

10. Dorsey E, Jarjoura D, Rutecki G: Influence of controllable lifestyle on recent trends in specialty choice by US medical students. JAMA 2003, 290(9): $1173-1178$.

II. Richardson HC, Redfern N: Why do women reject surgical careers? Ann R Coll Surg Engl 2000, 82(9 Suppl):290-3.

12. Odusanya OO, Nwawolo CC: Career aspirations of house officers in Lagos, Nigeria. Med Educ 200I, 35(5):482-7.

13. Lawrence J, Poole P, Diener S: Critical factors in career decision making for women medical graduates. Med Educ 2003, 37(4):319-27.

14. Wendel TM, Godellas, Prinz RA: Are there gender differences in choosing a surgical career? Surgery 2003, I34(4):59|-6. discussion 596-8

15. Gill D, Palmer C, Mulder R, Wilkinson T: Medical student career intentions at the Christchurch School of Medicine. The New Zealand Wellbeing, Intentions, Debt and Experience (WIDE) survey of medical students pilot study. Results part II. N Z Med J 200I, I | 4( I | 42):465-7.

16. Minor S, Poenaru D, Prk J: A study of career choice patters among Canadian medical students. Am J Surg 2003, 186(2): $182-8$.

17. Donnelly MB, Jarecky RK, Rubeck R, Murphy-Spencer A, Parr P, Schwartz RW: Factors influencing medical students' choice of academic medicine as a career. J Ky Med Assoc 1996, 94(5): $186-90$.

18. Neumayer L, Kaiser S, Anderson K, Barney L, Curet M, Jacobs D, Lynch T, Gazak C: Perceptions of women medical students and their influence on career choice. Am J Surg 2002, I 83(2): I 46-50.

19. Lambert TW, Goldacre MJ, Davidson JM, Parkhouse J: Graduate status and age at entry to medical school as predictors of doctor's choice of long-term career. Med Educ 200I, 35(5):450-4.

20. Buddeberg-Fischer B, Klaghofer R, Abel T, Buddeberg C: The influence of gender and personality traits on the career planning of Swiss medical students. Swiss Med Wkly 133(39-40):535-40. 2003 Oct II

21. Kassebaum DG, Szenas PL: Medical student's career indecision and specialty rejection: roads not taken. Acad Med 1995, 70(10):937-43.

22. [http://www.bma.org.uk/ap.nsf/Content/DemographyMedSchls/\$file/ demography.pdf]. British Medical Association Website, (Demographic Data), Accessed July 2006.

\section{Pre-publication history}

The pre-publication history for this paper can be accessed here:

http://www.biomedcentral.com/1472-6920/7/2/prepub 